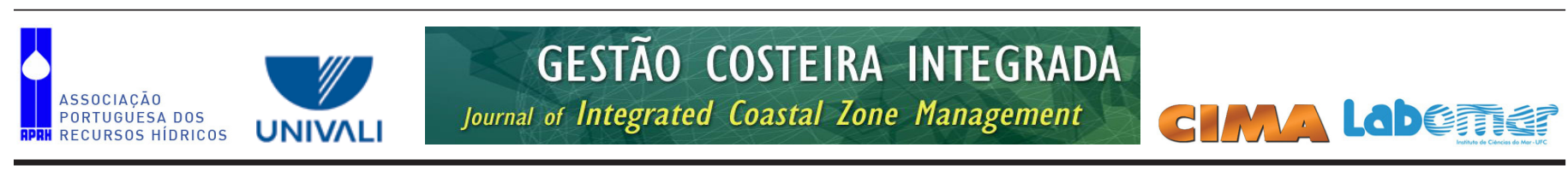

http://www.aprh.pt/rgci/pdf/rgci-398_Pereira.pdf | DOI:10.5894/rgci398

\title{
Avaliação experimental da influência de diferentes configurações da cabeça de quebramares destacados no comportamento morfológico da praia adjacente *
}

\author{
Experimental evaluation of the influence of detached breakwater head \\ configuration in the morphological behavior of the adjacent beach
}

\author{
Rui China Pereira ${ }^{\circledR, 1}$, F. Taveira Pinto ${ }^{1}$, Raquel Silva ${ }^{1}$, Luciana das Neves ${ }^{1}$
}

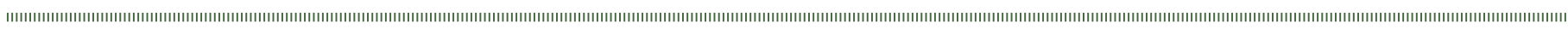

\section{RESUMO}

A costa atlântica portuguesa é submetida à ação da agitação marítima que se caracteriza por recorrentes tempestades de elevado potencial energético, que colocam em risco zonas urbanas, infraestruturas e áreas de significativo valor ecológico. A sua relevância a nível social, ambiental e económico para as comunidades locais e para o futuro de Portugal, obriga a que sejam definidos planos de intervenção na tentativa de proteger a linha de costa, minimizando o impacto da ação do mar. De modo a que o plano seja eficaz, é indispensável que exista um profundo conhecimento técnico e científico dos processos naturais em curso, bem como das possíveis soluçóes a aplicar.

O planeamento, definição e execuçáo de uma estrutura de defesa costeira dependem da capacidade e características dos equipamentos disponíveis e dos métodos construtivos utilizados. No entanto, a evolução ao longo dos anos de instrumentos e técnicas utilizadas, permite conceber novas soluçóes, de modo a adaptar as intervençóes tradicionais às maiores exigências atuais. É neste contexto que se enquadram as estruturas destacadas que procuram não só proteger a zona costeira através da redução da energia da agitação incidente, mas também contribuir para a melhoria das condiçôes balneares e ajudar à rehabilitação dos ecossistemas locais.

Os quebramares destacados são, por norma, estruturas alinhadas de forma aproximadamente paralela à linha de costa, que funcionam como uma barreira à normal propagação da agitação incidente. A sua posição em relação à linha de costa interfere com a normal progressão da onda, reduzindo a altura e a energia da onda que por si passa em direção à zona de sombra. No seu dimensionamento, deve ser estudada a interação onda-estrutura, dependente dos parâmetros funcionais do quebramar (ex.: comprimento, orientação e distância à linha de costa), que determinam a eficiência da sua ação em termos de proteção e de controlo da erosão costeira. Com o objetivo de avaliar a eficiência dos quebramares destacados como estruturas de defesa costeira na costa oeste portuguesa, deu-se início a uma série de estudos na Secção de Hidráulica, Recursos Hídricos e Ambiente (SHRHA), do Departamento de Engenharia Civil (DEC), da Faculdade de Engenharia da Universidade do Porto (FEUP). Num primeiro estudo foi proposto um quebramar destacado como soluçáo de proteção para a frente urbana de Espinho. Na sequência deste estudo, foi efetuada a simulação numérica das condiçóes hidrodinâmicas e morfodinâmicas, comparando-se a situação presente com o cenário de implantação do quebramar proposto. Os resultados das simulaçóes sugeriram a necessidade de testar outras configuraçóes para o quebramar e avaliar a sua influência na praia adjacente. O presente trabalho procurou analisar a influência da configuração da cabeça do quebramar destacado na evolução morfológica do perfil de praia adjacente, através de ensaios em modelo físico.

\section{@- Corresponding author}

1 - Departamento de Engenharia Civil, Faculdade de Engenharia da Universidade do Porto, Rua Dr. Roberto Frias, Porto, 4200-465, Portugal. e-mails: Pereira-rchina@fe.up.pt; Pinto - fpinto@fe.up.pt; Silva-rfsilva@fe.up.pt; Neves - lpneves@fe.up.pt 
Especificamente, foi testada a influência de 3 configurações da cabeça de um quebramar destacado na evolução de uma praia, quando submetido a duas condiçóes de agitação características da costa oeste portuguesa, em modelo físico com fundos móveis. Nos ensaios realizados, não foram observadas diferenças significativas nos padróes de transporte sedimentar em torno da estrutura. A areia transportada é retirada de zonas ao longo das faixas laterais à estrutura, sendo depositada na zona de sombra, ao longo do eixo central do modelo, mantendo-se assim constante o volume total de areia na praia. A ocorrência de galgamentos em alguns testes, com uma altura de onda significativa maior, instabiliza o padrão de recirculação de correntes na zona abrigada pelo quebramar, reduzindo a expressão das alteraçóes observadas. Os resultados ilustraram que a configuração da cabeça do quebramar com forma cónica e declive menos acentuado tem um efeito positivo na estabilidade global da estrutura, minimizando as erosóes localizadas na base dos taludes.

Palavras-Chave: Quebramares Destacados; Modelação Física; Evolução Morfológica; Linha de Costa; Laboratório de Hidráulica da FEUP.

\section{ABSTRACT}

The Atlantic coast of Portugal is exposed to rough wave climate conditions and frequently submitted to powerful storms, endangering waterfronts, infrastructures and natural landscapes. Due to the social, environmental and economic significance of these areas to the local communities and to the national progress, measures must be taken by the decision-makers to control and reduce the negative impacts from the wave action. In order to define effective plans, it is important that technical and scientific aspects of the natural processes are understand, as well as the impacts of the proposed solutions.

The planning, the design and the construction processes of a coastal structure depend on the characteristics and potential of the available equipment and of the construction methods applied. Over the years, new instruments and innovative techniques, allow the conception of new solutions, in order to adapt traditional interventions to the present demands. In this context, the detached breakwaters are known as structures that not only provide shelter from the waves, inducing the wave energy reduction, but that can also improve bathing conditions and local habitats adaptation.

A detached breakwater can, in general terms, be described as a coastal structure, built inside/near the surf zone, having an approximate orientation parallel to the coast. Due to its relative position to the coastline, the structure interferes with the normal wave propagation, reducing wave height and wave energy in the lee zone. During the design process of these structures, it is important to consider the wave-structure interaction, defined by their functional parameters (e.g.: length, orientation and distance to the shoreline), that establish their efficiency. Aiming to evaluate the efficiency of detached breakwaters as coastal defence structures in the west coast of Portugal, a series of studies was initiated in the Hydraulics, Water Resources and Environment Division (SHRHA), of the Civil Engineering Department (DEC), of Faculty of Engineering, University of Porto (FEUP). Firstly, a detached breakwater was proposed for the defence of the urban front of Espinho, located on the northwest coast of Portugal. Following this study, numerical simulation of the hydrodynamic and the morphodynamic conditions were performed. The present situation was compared with a scenario of implantation of the proposed breakwater. Simulation results suggested the need to test different configurations for the detached breakwater. This way, the physical modelling research study, here described, was conducted in order to analyse the effect of different configurations of, coastline parallel, detached structures in the adjacent coastline/beach.

Specifically, the influence of three different configurations for the head of a detached breakwater, when subjected to two wave conditions typical of the west coast of Portugal, was tested in a movable bed physical model. In the experimental tests, no significant differences were observed in the sediment transport patterns surrounding the structure. The transported sand was removed from lateral strips, being deposited in the breakwater lee, along the central axis of the model. The total volume of sand of the beach was maintained. The occurrence of overtopping in some of the tests, with higher significant wave heights, imbalances the recirculation currents patterns in the lee of the structure, reducing the expression of the registered changes. The results showed that the conical configuration of the breakwater head, with lower slopes, has a positive effect in terms of the overall stability of the structure and minimizes localized erosion in the breakwater toe.

Keywords: Detached Breakwater, Physical Modelling, Morphological Evolution, Coastline, Hydraulics Laboratory of FEUP.

\section{INTRODUÇÃO E ENQUADRAMENTO}

Um quebramar destacado é, de modo geral, definido como uma estrutura alinhada de forma aproximadamente paralela à linha de costa, geralmente implantada na zona de rebentação, que funciona como uma barreira à normal propagação da onda em direção à zona costeira (e.g., Mangor, 2004), protegendo infraestruturas, frentes urbanas ou áreas de significativo valor ambiental e daí o interesse do seu estudo para a gestão das zonas costeiras(e.g., Gomes et al., 2006; Gomes, 2007; Pereira, 2013).

Existem diversas configuraçóes de quebramares destacados, ajustadas às diferentes funçốes e objetivos, que podem ir desde o guiamento de correntes marítimas ou fluviais, ao estabelecimento/manutenção de canais de navegação, ou ainda, à proteção de infraestruturas e frentes urbanas.
A sua missão enquanto estrutura de defesa costeira é proteger a linha de costa adjacente através da redução da energia de onda incidente, conduzindo à redistribuição do padrão de transporte de sedimentos, de modo a criar a configuraçáo de praia desejada (e.g., Taveira-Pinto, 2002). $\mathrm{O}$ seu alinhamento interfere com a normal propagação da agitação em direção à linha de costa, induzindo a reflexão e a rebentação da onda incidente, que dão origem à difração em torno das suas extremidades. Com efeito, estes fenómenos resultam numa transferência lateral de energia entre a zona exposta e a zona abrigada pela estrutura. Estes processos são acompanhados pela ocorrência de correntes de recirculação na zona abrigada, que promovem o transporte sedimentar e o consequente reajustamento morfológico, entre a linha de costa e o quebramar. A deposição de sedimentos acontece ao 
longo de um eixo ortogonal à estrutura, partindo de terra em direção à estrutura, formando uma saliência. No caso do fator de reduçáo da energia de onda induzido pela estrutura ser elevado, a saliência formada pode chegar ao talude de tardoz do quebramar, fixando uma ligaçáo permanente à linha de costa que se designa por tômbolo.

Os quebramares destacados são estruturas de defesa costeira eficientes em zonas caracterizadas por um clima de agitação ameno/moderado e por uma pequena amplitude de maré. No entanto, a sua utilização em zonas de maior exposição à agitação marítima e/ou com maior amplitude de maré, deve ainda ser estudada, de forma a aperfeiçoar a sua configuração e definir o melhor método construtivo, de acordo com as solicitaçóes e características locais (e.g., Taveira-Pinto, 2002).

O desempenho de um quebramar deve ser avaliado de acordo com os impactos na linha de costa adjacente, náo esquecendo porém a segurança e estabilidade da própria estrutura. A eficácia da sua ação é influenciada por diversos parâmetros característicos do quebramar, como o comprimento, largura e cota do coroamento, a distância à linha de costa e o grau de submergência da estrutura, mas também pelas características da zona envolvente, das quais se destacam a amplitude de maré, o nível médio das águas ou as características da agitação. De facto, tais características serão determinantes para a ocorrência de outros fenómenos de interação, como o galgamento e o fluxo de água através dos vazios existentes ao longo do corpo do quebramar (e.g., Burcharth et al., 2007). A ocorrência de fenómenos como o galgamento, representam uma diminuição do fator de redução da energia incidente proporcionado pelo quebramar, interferindo no padráo de distribuiçáo sedimentar e proporcionando também a entrada de um volume adicional de água na zona de sombra, benéfico em zonas de agitação mais moderada, impedindo a estagnação das águas na zona protegida. Taveira-Pinto, (2002) e Neves (2008) apresentam um extenso estado da arte em relação a estes tópicos.

A reconfiguração morfológica na área envolvente, decorrente da ação hidráulica da estrutura, tem um significativo impacto sobre a corrente longitudinal de transporte sedimentar. $\mathrm{O}$ grau de influência da estrutura depende de características da estrutura, como o comprimento do quebramar ou a distância da estrutura à linha de costa, mas também das peculiaridades da zona de implantação do quebramar. Assim, as estruturas destacadas podem ser caracterizadas por parâmetros, como a distância à linha de costa relativamente à largura da zona de rebentaçáo $\left(x^{*}\right)$ e o comprimento do quebramar relativamente à distância à linha de costa $\left(L_{B}^{*}\right)$ (Mangor, 2004).

$$
\begin{aligned}
& \mathrm{L}_{\mathrm{B}}{ }^{*}=\mathrm{L}_{\mathrm{B}} / \mathrm{x} \\
& \mathrm{x}^{*}=\mathrm{x} / \mathrm{x}_{80}
\end{aligned}
$$

em que $L_{B}$ representa o comprimento do quebramar, $x$ a distância à linha de costa $\mathrm{e}_{80}$ a largura da zona de rebentação, onde se verifica aproximadamente $80 \%$ do transporte sedimentar longitudinal.
Segundo Mangor (2004), quando o valor de $\mathrm{L}_{\mathrm{B}}{ }^{*}$ for menor que 0,7 , forma-se uma saliência, enquanto que se o valor desta relação for maior que 0,9 , a acumulação de sedimentos na zona protegida pode conduzir à formaçáo de um tômbolo. No entanto, devido à complexidade dos fenómenos envolvidos e a especificidade das características locais, os valores definidos podem não representar o caso de estudo. $\mathrm{O}$ autor defende ainda que os quebramares destacados podem ser classificados mediante a sua função e de acordo com a sua distância relativa à linha de costa, estabelecendo que, um quebramar externo $\left(\mathrm{x}^{*}>3,0\right)$ representa uma estrutura construída fora da zona de rebentação, sendo a sua influência sobre o transporte longitudinal de sedimentos insignificante. Um quebramar de praia $\left(\mathrm{x}^{*}<0,5\right)$, representa uma estrutura que está numa posição muito próxima da linha de costa, sendo a largura da zona de rebentação pelo menos duas vezes superior a esta distância. Neste caso, o transporte longitudinal não é significativamente afetado, apesar da deposição de areias na zona sombra do quebramar, uma vez que este apenas interfere numa pequena parcela da faixa ao longo da qual esse transporte se verifica. Os quebramares costeiros $\left(0,5<\mathrm{x}^{*}\right.$ $<2,0)$ podem funcionar como zonas tampão, bloqueando a passagem de sedimentos para sotamar. Nestes casos, devem ser tomadas medidas no sentido de restabelecer o normal transporte de sedimentos ao longo da costa.

Assim, como foi já referido, os quebramares destacados, total ou parcialmente submersos, podem constituir um meio eficaz de proteção contra a ação da agitação marítima nas zonas costeiras e portuárias. De facto, estes quebramares, submersos ou não, também designados de pequena altura de água acima da crista podem, por exemplo, possibilitar uma solução de defesa costeira localizada ou de estabilização de praias alimentadas artificialmente, devido à atenuação parcial da agitação na zona de sombra do quebramar. Esta barreira pode assim diminuir os galgamentos na linha de costa e as consequentes inundaçóes de zonas residenciais costeiras. Um quebramar destacado, dependendo das suas características é parcial ou totalmente impermeável à agitação marítima e, consequentemente, a transmissão dessa agitação em direção à linha de costa é consideravelmente menor.

Estes aspetos são de especial relevância em zonas sujeitas ao fenómeno da erosáo costeira e para as quais, a opçâo de gestão por via da proteçấo através deste tipo de estruturas são uma opção a considerar.

Contudo, antes de uma tomada de decisão final, é tâo importante conhecer as vantagens como as desvantagens da sua utilização, nomeadamente qual o grau de atenuação da agitação marítima previsto, qual a transmissão efetiva, como se movem os sedimentos nas suas imediaçóes e qual a influência das dimensôes e características da estrutura nesse processo de transporte sedimentar, que é talvez um dos aspetos mais críticos, visto que a estrutura será construída para fins de proteção costeira.

A caracterização da agitação efetuada nas imediações destes quebramares traduz a abordagem convencional do estudo dessa dissipação, fornecendo, sob a forma de coeficientes de reflexão, transmissão e dissipação, informaçôes úteis sobre essa caracterização. Contudo, não fornece informaçôes sobre o escoamento, o campo de velocidades, nem o transporte sedimentar. 
Daí que o objetivo deste trabalho de investigação seja conhecer com melhor detalhe, para algumas situaçóes de teste, essa interação agitação marítima-estrutura-sedimentos e verificar de que forma as características geométricas da estrutura têm influência nessa interação e de que forma uma correta definição em termos de projeto pode evitar alguns dos possíveis impactos negativos ou melhorar os positivos. Desta forma o projetista poderá auxiliar o processo de gestáo costeira do troço em estudo em relaçáo ao aspeto particular da erosão costeira.

Foram então realizados, na Secção de Hidráulica, Recursos Hídricos e Ambiente (SHRHA), do Departamento de Engenharia Civil (DEC), da Faculdade de Engenharia da Universidade do Porto (FEUP), alguns estudos sobre interação agitação marítima-estrutura-sedimentos. Num primeiro estudo (Pereira, 2008) foi proposto um quebramar destacado como solução de proteçâo para a frente urbana de Espinho. Na sequência deste estudo, foi efetuada a simulação numérica das condiçóes hidrodinâmicas e morfodinâmicas, comparando-se a situação presente com o cenário de implantação do quebramar proposto (Costa, 2009). Os resultados das simulaçóes sugeriram a necessidade de testar outras configuraçóes para o quebramar e avaliar a sua influência na praia adjacente. $\mathrm{O}$ presente trabalho procurou analisar a influência da configuração da cabeça do quebramar destacado na evolução morfológica do perfil de praia adjacente, através de ensaios em modelo físico.

\section{INSTALAÇÃO EXPERIMENTAL}

\subsection{Equipamento Utilizado}

O estudo realizado tinha como objetivo interpretar a resposta morfológica de um modelo de um quebramar destacado, exposto a condiçóes de agitação características da orla costeira portuguesa. Os ensaios realizaram-se no Laboratório de Hidráulica (LH) da Secção de Hidráulica, Recursos Hídricos e Ambiente (SHRHA) do Departamento de Engenharia Civil (DEC) da Faculdade de Engenharia da Universidade do Porto (FEUP). O tanque de ondas do LH, Figura 1, ocupa uma área em planta de $28 \times 12 \mathrm{~m}^{2}$, estando circunscrito por paredes com $1,20 \mathrm{~m}$ de altura que permitem a execução de ensaios de modelos a duas ou três dimensôes.

$\mathrm{O}$ tanque de ondas do $\mathrm{LH}$ está equipado com um sistema de geração de agitação, modelo HR Wallingford. É constituído por uma série de pás independentes, cujo movimento é controlado por um motor elétrico, e permite um vasto leque de opçôes, para que seja possível reproduzir os climas de agitação pretendidos. $\mathrm{O}$ movimento individual de cada uma das pás é independente podendo funcionar em sintonia ou de forma singular. É assim possível representar diferentes tipos de agitação, de entre os quais se destacam: as ondas regulares, a agitaçáo irregular baseada em espectros definidos, a ondulaçáo bidirecional e ainda ondas cuja crista faz um ângulo em relação à perpendicular do alinhamento das pás. Para o presente trabalho foram considerados apenas estados irregulares de agitaçáo, uma vez que estes representam, de forma satisfatória, as condiçōes de mar geradas em ambiente natural. A informação necessária para definir o movimento das pás é a profundidade de água no tanque, a altura de onda significativa, o período de pico e o tipo de espectro pretendido.

No interior do tanque, do lado oposto ao sistema gerador, existe uma praia em gravilha e cascalho, com o objetivo de dissipar a energia da agitação incidente. $\mathrm{O}$ software de controlo do sistema de geraçâa possui também uma opção que procura compensar os efeitos de reflexão no próprio batedor, contribuindo, em conjunto com a praia dissipadora, para a neutralização deste fenómeno.

No sentido de recolher informação relativa à evolução morfológica do perfil de praia junto à estrutura, foi utilizado um sistema de medição de fundos, modelo HR Wallingford. $\mathrm{O}$ equipamento permite o registo do perfil com recurso a diferentes técnicas, sendo que a seleção recaiu sobre a utilização de uma sonda de medição sensível ao toque. A

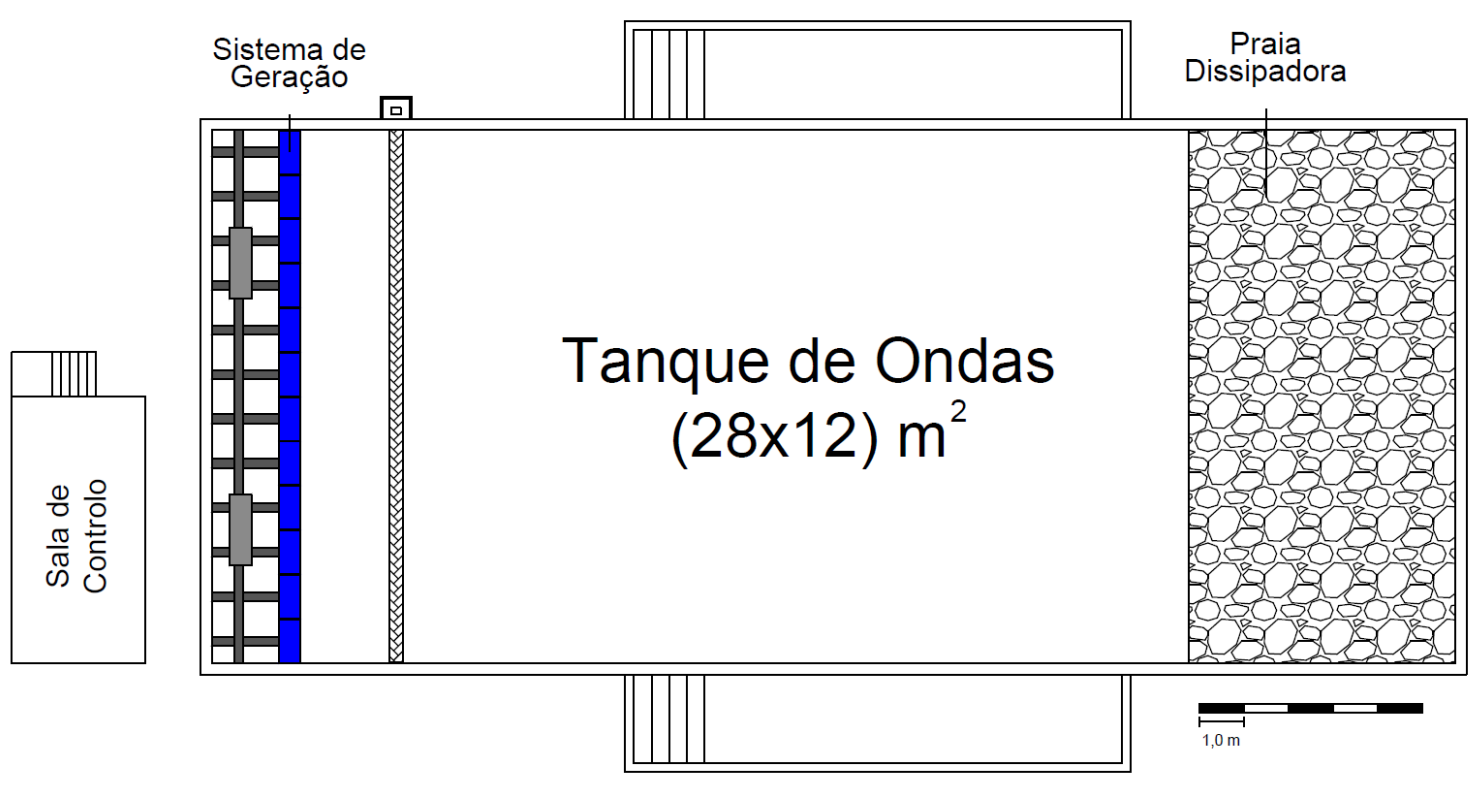

Figura 1. Tanque de ondas do LH da SHRHA-DEC-FEUP.

Figure 1. Wave tank of the LH of SHRHA-DEC-FEUP. 
seleçấo baseou-se na experiência transmitida por estudos anteriores (Silva, 2010), em que foi possível constatar, após a realização de alguns testes preliminares, que essa opção era a mais indicada para a leitura de perfis em modelos de fundos móveis. Foram definidas posições paralelas e afastadas de 1 $\mathrm{m}$ entre si, para medição dos perfis, segundo uma direção perpendicular, relativamente à orientação do quebramar destacado e da crista da onda à saída do gerador.

$\mathrm{O}$ equipamento transmite a informação registada, nomeadamente o deslocamento vertical da haste anexa à sonda e o deslocamento horizontal da caixa de rolamentos que proporciona o movimento do conjunto. $\mathrm{O}$ deslocamento vertical é medido considerando a distância percorrida ao longo da haste desde a sua posição inicial até que a sonda toque a superfície da praia. Por sua vez o deslocamento horizontal é calculado com base na informação previamente disponibilizada referente ao comprimento total do perfil selecionado e ao número de registos que se pretendem obter ao longo do mesmo. Através da informação recolhida, o software elabora uma tabela de dados conjugando os valores dos deslocamentos medidos através dos quais é possível obter o perfil desejado.

A resoluçáo do perfil obtido segundo a vertical é de 0,0005m enquanto, segundo a horizontal a distância mínima entre pontos é de $0,001 \mathrm{~m}$. Os perfis construídos tinham uma extensão total de $3,9 \mathrm{~m}$, ao longo dos quais era retirada informação em 70 pontos, o que representa um espaçamento de cerca de $0,0557 \mathrm{~m}$.

\subsection{Modelo}

$\mathrm{O}$ modelo 3D implantado no tanque de ondas, Figura 2, foi construído com o objetivo de ajudar a compreender o grau de influência do quebramar destacado na evolução morfológica da praia adjacente. A sua definição física procurou conjugar o espaço e materiais disponíveis com as dimensóes do modelo, de forma a favorecer a leitura dos resultados obtidos e consequente comparação dos resultados referentes aos diferentes testes realizados.

O modelo foi construído de acordo com a escala geométrica de $1 / 40$, de forma a serem reaproveitados na sua construção materiais que se encontravam já disponíveis no $\mathrm{LH}$, não comprometendo no entanto a pretensa ligação às condiçôes físicas características das faixas de praia da zona noroeste da costa portuguesa. Uma vez definida a escala e o critério de semelhança mais representativo (semelhança de Froude), foram calculadas, através da fórmula de Hudson, as dimensóes características dos blocos de enrocamento a colocar no manto resistente da estrutura. Estas opçóes de definição do modelo físico 3D foram baseadas num estudo anteriormente realizado, para a medição da evolução de um perfil de praia sob a ação de diferentes condiçôes de agitação (Silva, 2010).

A distância lateral entre o quebramar construído e a fronteira física do tanque considerada procurava garantir que o contorno da estrutura por parte da onda ocorria de forma natural sem que fosse constrangido pela parede lateral do tanque. Esta análise conduziu a que o espaço lateral mínimo, medido desde a estrutura até à parede do tanque de ondas, tinha de ser igual ou superior ao comprimento de onda

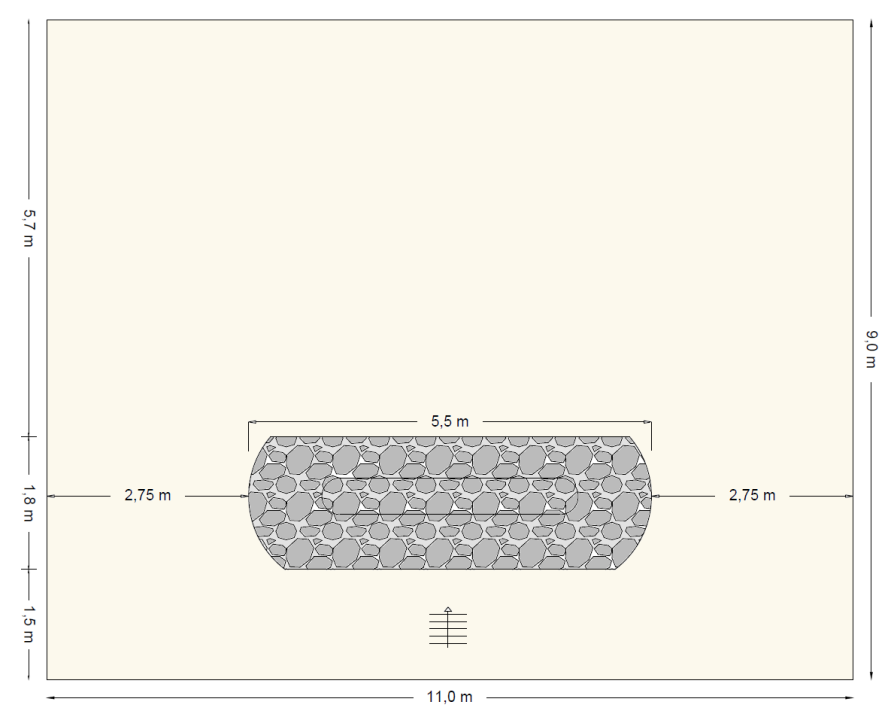

Figura 2. Planta de implantação do modelo (China, 2011). Figure 2. Implantation map of the model (China, 2011).

máximo registado para as condiçóes testadas. Desta forma procurou-se minimizar o efeito da reflexão que pudesse existir nas paredes do tanque, que poderia levar a alteraçōes no padrão de redistribuição sedimentar no perfil de praia estudado.

As configurações atribuídas à estrutura foram selecionadas tendo em atençâo soluçôes tradicionalmente utilizadas, Figura 3. As variaçóes induzidas centraram-se na zona da cabeça da estrutura, devido à sua particular influência no que se refere à estabilidade e ao padrão de propagação da onda para sotamar. Desta forma, a orientação paralela do quebramar em relação à crista da onda incidente, o alinhamento reto, as inclinaçóes dos taludes anterior e posterior, a cota de coroamento e a largura e comprimento do mesmo foram mantidos em todas as configuraçôes ensaiadas, Tabela 1.

Tabela 1. Características do quebramar ensaiado.

Table 1. Characteristics of the tested breakwater.

\begin{tabular}{lccc}
\hline & Modelo & Protótipo \\
\hline Cota de Coroamento & 0,125 & & $+6,0 \mathrm{ZH}$ \\
\hline Pendente do Talude Exposto & & $1 / 2$ & \\
\hline Pendente do Talude Posterior & & $2 / 3$ & \\
\hline Comprimento do Coroamento & $3,0 \mathrm{~m}$ & & $120 \mathrm{~m}$ \\
\hline Largura de coroamento & $0,50 \mathrm{~m}$ & $2,0 \mathrm{~m}$ \\
\hline
\end{tabular}

Neste estudo foram consideradas diferentes configuraçóes para o quebramar, Figura 3, correspondendo a três configuraçóes distintas do perfil da zona da cabeça do quebramar, dando origem a três modelos diferentes.

A primeira configuração base procurava representar um tipo de estrutura onde as transiçóes entre taludes adjacentes fossem representadas por um alinhamento reto. Nesta opção 

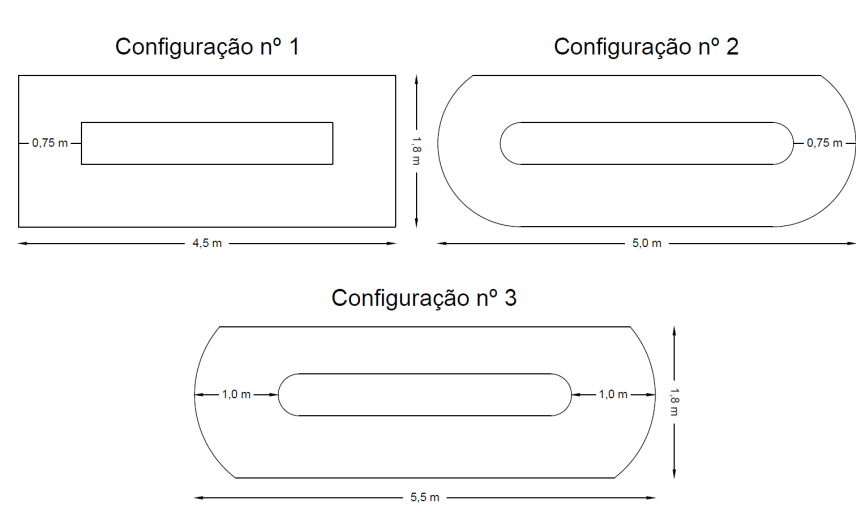

Figura 3. Configuraçôes do quebramar destacado (China, 2011). Figure 3. Configurations of the detached breakwater (China, 2011).

a inclinação do talude da zona de cabeça do quebramar apresentava uma pendente igual à definida para o talude exposto, Figura 3 (em cima, à esquerda).

A primeira alteração consistiu na substituição do talude retilíneo por uma zona de transição entre as faces anterior e posterior da estrutura que eliminava os alinhamentos da primeira configuração, conferindo uma forma cónica à cabeça da estrutura, Figura 3 (em cima, à direita). Esta configuração mantinha, no entanto, a pendente do talude nestas áreas inalterada e igual à imposta para o talude exposto do quebramar. Com esta alteraçáo, pretendia-se proporcionar uma adaptação progressiva da onda incidente às mudanças que ocorriam no talude, ao invés da transiçáo brusca induzida pela primeira solução.

Posteriormente foi considerada uma segunda alteração que deu origem à terceira configuração ensaiada, envolvendo mudanças na pendente do talude lateral da estrutura. Relativamente à situação de base foi de novo operada a alteração proposta na situação anterior, relativa à supressão das transiçóes entre faces da estrutura baseadas em alinhamentos retilíneos, sendo estes substituídos por uma transição progressiva entre taludes que confere uma forma cónica à zona de ligação da parte exposta à área protegida do quebramar. Desta vez, foi também modificada a inclinação do talude lateral da cabeça da estrutura atenuando a sua pendente dos anteriores $1 / 2$ para valores na ordem dos $3 / 8$, Figura 3.

A secção do quebramar construído foi mantida constante em todas as configuraçōes, Figura 4.
O quebramar foi construído segundo o plano apresentado, sendo constituído por 3 diferentes camadas. $\mathrm{O}$ núcleo da estrutura foi materializado com sacos de geotêxtil permeáveis cheios de areia, que procuravam dar volume ao espaço interior do modelo e facilitar a definiçáo dos taludes. Depois dos geotêxteis foi disposta uma camada de brita, de dimensóes reduzidas, que simulava a $1^{\text {a }}$ subcamada de uma solução real. A colocaçáo deste material permitiu conferir desde logo a pendente pretendida para cada talude.

$\mathrm{O}$ revestimento da estrutura foi organizado de forma mais seletiva, tendo sido definido numa fase prévia o peso dos blocos, Tabela 2, representando em protótipo blocos com um peso compreendido ente as 11 e as 15 toneladas $(110$ a $150 \mathrm{kN})$.

Neste trabalho foi usada uma areia de sílica da empresa SIBELCO Portuguesa, Lda., com uma baridade de $1037 \mathrm{~kg} / \mathrm{m}^{3}$ e um diâmetro médio $\left(d_{50}\right)$ igual a $0,273 \mathrm{~mm}$. $\mathrm{Na}$ Figura 5, apresenta-se a curva granulométrica da areia utilizada, Silva (2010).

A caracterização sedimentar da areia da praia a utilizar no modelo constitui uma condição fundamental para que os resultados obtidos possam depois ser extrapolados e interpretados à escala real. Com efeito, esta interpretação depende da escala considerada, do diâmetro médio $\left(d_{50}\right)$, dos critérios de semelhança adotados e do modo de transporte sedimentar considerado dominante (Silva, 2010). No entanto, o objetivo do trabalho aqui apresentado era a realização de uma análise comparativa entre os resultados dos ensaios realizados para diferentes configurações do quebramar. Assim, uma vez que foram usados os mesmos materiais e que os parâmetros de ensaio não foram alterados, os resultados vêm afetados dos mesmos efeitos, sendo válida a sua análise comparativa.

\section{PROCEDIMENTO}

Os resultados obtidos em cada teste seriam comparados entre si. Para tal, foi necessário garantir que as condiçóes hidrodinâmicas e morfológicas de cada ensaio eram idênticas e, portanto, garantir a repetiçẫo dos procedimentos e tarefas em todos os ensaios.

Foram definidos 5 alinhamentos, ao longo dos quais, utilizando o sistema perfilador anteriormente referido, foi recolhida informação relativa à evolução dos perfis de praia, Figura 6.

Os perfis estavam dispostos perpendicularmente à orientação da crista da onda incidente e eram paralelos entre si,

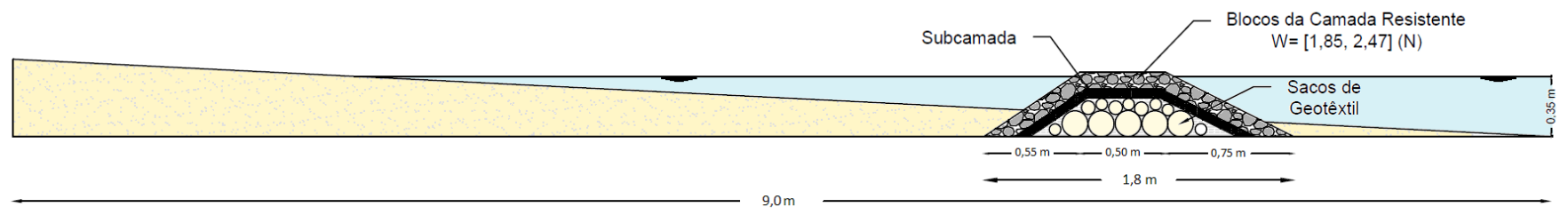

Figura 4. Secção transversal tipo do modelo (China, 2011).

Figure 4. Cross section of the model (China, 2011). 
Análise Granulométrica SP55 - Sibelco Portuguesa Lda.

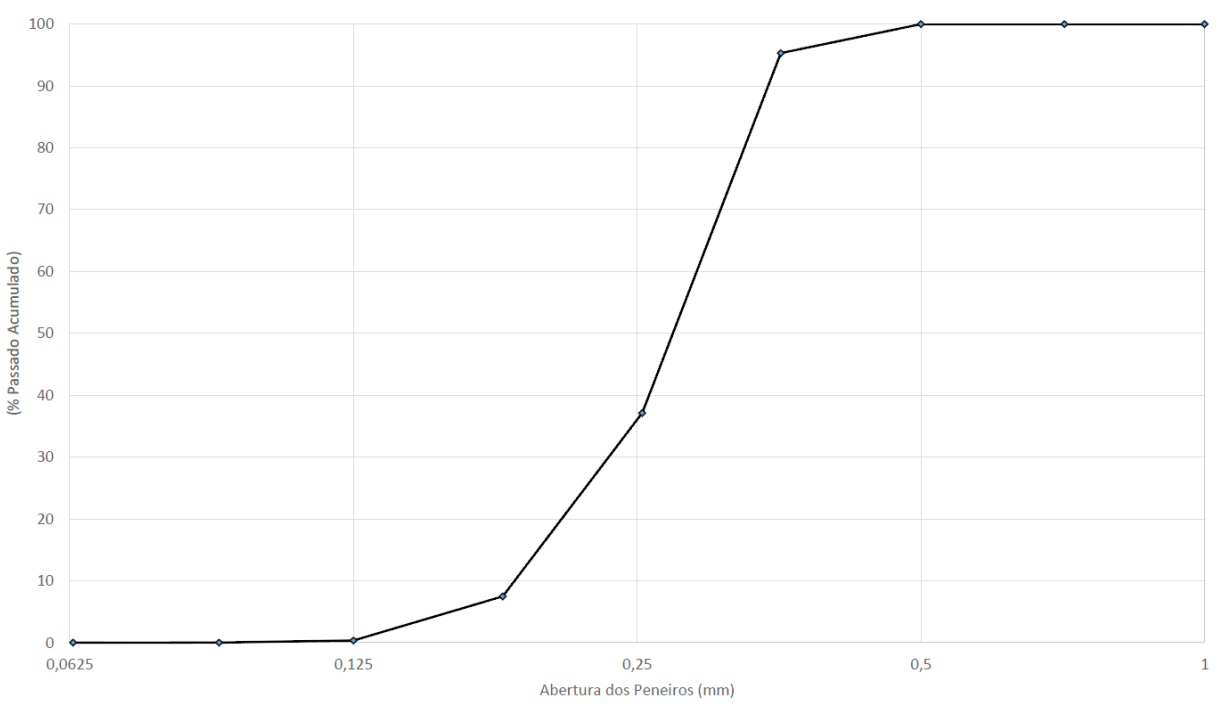

Figura 5. Curva granulométrica da areia SP55 - SIBELCO Portuguesa, Lda.

Figure 5. Grading curve of the sand SP55 - SIBELCO Portuguesa, Lda.

Tabela 2. Características dos blocos do manto resistente.

Table 2. Armor layer blocks characteristics.

\begin{tabular}{lcc}
\hline & \multicolumn{1}{c}{ Modelo } & Protótipo \\
\cline { 2 - 3 } Peso dos Blocos do Manto Resistente $\left(W_{\text {manto }}\right)$ & {$[1,85$ a 2,47] $(\mathrm{N})$} & {$[110$ a 150] $(\mathrm{kN})$} \\
\cline { 2 - 3 } Dimensáo Média Característica $($ Blocos $)$ & $4,5(\mathrm{~cm})$ & $1,8(\mathrm{~m})$ \\
\cline { 2 - 3 } Espessura do Manto Resistente $\left(\boldsymbol{e}_{\Delta, \text { Manto }}\right)$ & $9,0(\mathrm{~cm})$ & $2,60(\mathrm{~m})$ \\
\hline
\end{tabular}

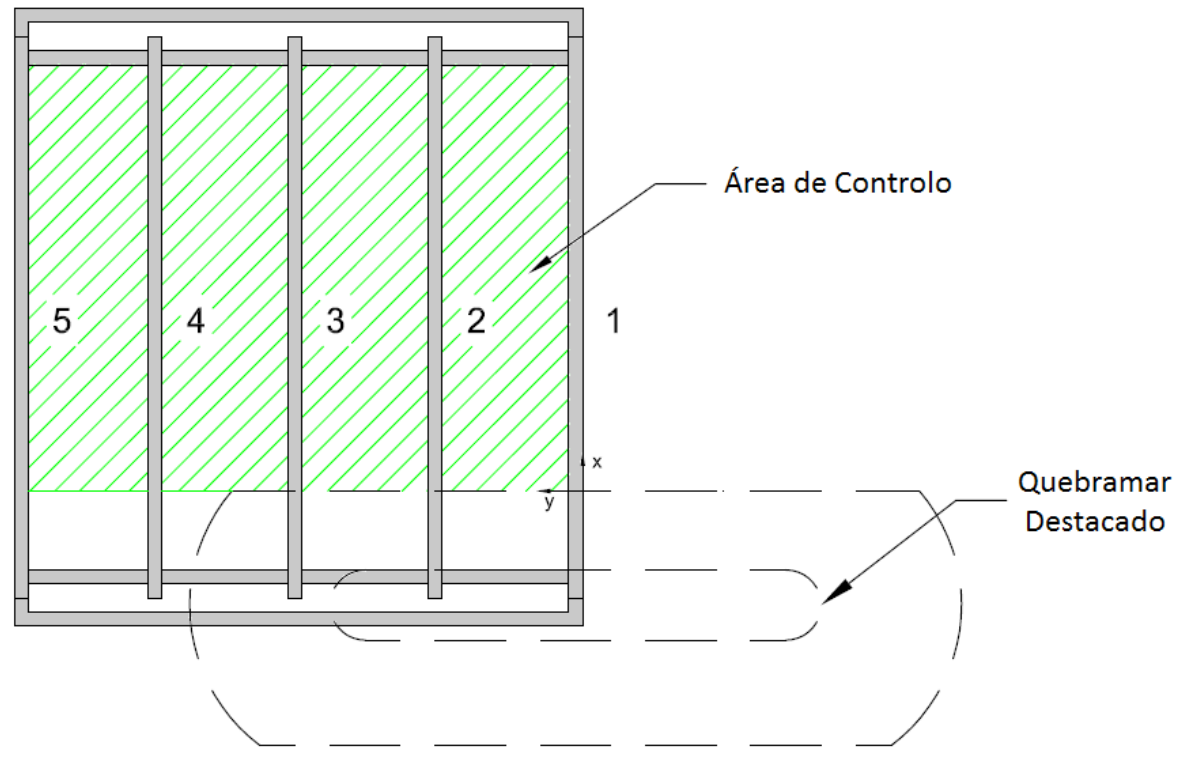

Figura 6. Planta do modelo e área de controlo (China, 2011). Figure 6. Plan and control area of the model (China, 2011). 
espaçados de $1 \mathrm{~m}$. Devido à simetria apresentada pelo modelo construído e ao facto da orientaçáo de agitação a que este foi submetido ser ortogonal ao alinhamento do quebramar, admitiu-se que as alteraçóes morfológicas que se verificavam eram também elas simétricas em relação ao eixo longitudinal principal do tanque, que passava (transversalmente) pelo centro do modelo com base nesse pressuposto a área de medição e o número de perfis controlados era menor e, consequentemente, uma redução do tempo necessário à recolha de informação sobre os mesmos, e do tempo total de ensaio.

As condições de ensaio foram definidas atendendo à representatividade de estados de agitação registados na costa portuguesa (Costa et al., 2001), mas também às características físicas do tanque de ondas. Os estados de agitação gerados simulavam sequências de ondas irregulares definidas pelo espectro de Jonswap, com um período de pico $\left(T_{p}\right)$ de $1,58 \mathrm{~s}$ em modelo, correspondendo a 10 s à escala real. As alturas de onda significativas $\left(H_{s}\right)$ geradas eram de 0,075 e $0,125 \mathrm{~m}$ no modelo, que representam alturas de 3 e $5 \mathrm{~m}$ na realidade. O comprimento de onda associado ao período característico definido enquadra-se no espaço lateral existente, estando assim garantido o critério limite definido para a distância lateral entre a estrutura e o limite físico do tanque.

Os ensaios tinham uma duração média de 13/14 horas, correspondendo 8 dessas horas a tempo efetivo de ensaio e as restantes $4 / 5$ horas a períodos de recolha de perfis. Assim sendo, e de acordo com a escala do modelo, o tempo correspondente em protótipo ultrapassaria as 50 horas de solicitação sobre a praia, ou seja, mais de 2 dias.

No entanto, este tempo é considerado por Chen \& Kuo (1994) como insuficiente para que a praia atinja a situação de equilíbrio. Segundo os autores este só é alcançado quando o valor do cociente entre a duração da solicitação $(t)$ e o período de pico $\left(T_{p}\right)$ do estado de agitação se aproximar de 60 000, diferenciando duas fases distintas para a evolução da praia, até que esse valor seja atingido. Numa primeira fase, sucedem-se rápidas variaçóes do perfil de praia e dos volumes de areia movimentados. Esta fase estende-se no tempo, até que a relaçáo descrita se aproxime de valores na ordem dos 20000 . Ultrapassado este valor e até se atingir o equilíbrio, as alteraçóes registadas são de menor dimensão e tendem a estabilizar.

Para as condiçóes de ensaio referidas, de acordo com as orientaçóes da relação defendida pelos autores citados, a duração dos ensaios correspondentes a transiçôes de fase da evolução de praia eram as que se apresentam no Tabela 3 .

Como se pode observar, os intervalos de tempo necessários à estabilização completa do perfil de praia eram bastante extensos e a estes seria necessário acrescentar o tempo dedicado à recolha de perfis a cada 2 horas de solicitação do modelo, para completar o tempo total de ensaio. Devido às limitaçôes de tempo para a realização dos trabalhos, não teria sido possível executar todos os testes pretendidos, caso a duração dos mesmos fosse tão prolongada.

Uma vez que o objetivo ambicionado era a comparação de resultados, foi definido um valor para a duraçáo relativa dos ensaios da ordem dos 20000 , cobrindo assim a fase mais ativa da evolução do perfil da praia adjacente ao modelo. Deste modo, foi possível conseguir significativos movimentos sedimentares que podiam ser analisados e comparados, uma vez que as condições e duraçáo dos ensaios eram mantidas em todos os testes.

\section{ANÁLISE DE RESULTADOS}

\subsection{Análise comparativa}

Os ensaios realizados foram alvo de uma análise comparativa, de forma a evidenciar as diferenças de comportamento de 3 configuraçóes de um quebramar destacado quando exposto a 2 condiçóes de agitaçáo diferenciadas pela altura de onda significativa característica, Tabela 4. É possível assim, relacionar as alteraçôes ocorridas na configuração da praia adjacente com as configurações definidas, mas também interpretar a influência do estado de agitação nos resultados obtidos.

Tabela 3. Duração de ensaio necessária à estabilização do perfil de praia (Chen e Kuo, 1994).

Table 3. Required test duration for the stabilization of the beach profile (Chen e Kuo, 1994).

\begin{tabular}{ccc}
\hline Duraçáo de ensaio / $T_{p}$ & $\begin{array}{c}\text { Duraçáo de Ensaio (em modelo) } \\
\text { (horas) }\end{array}$ & $\begin{array}{c}\text { Duraçáo de Ensaio (em protótipo) } \\
\text { (horas) }\end{array}$ \\
\hline 20000 & 8,7 & 55,6 \\
\hline 60000 & 26,3 & 166,6 \\
\hline
\end{tabular}

Tabela 4. Definição dos testes efetuados.

Table 4. Test' definition.

\begin{tabular}{lll}
\hline & $\boldsymbol{H}_{s}=\mathbf{3 , 0} \boldsymbol{m}$ & $\boldsymbol{H}_{s}=\mathbf{5 , 0} \boldsymbol{m}$ \\
\hline Configuraçáo $\mathbf{n}^{\circ} \mathbf{1}$ & Teste 1 & Teste 2 \\
\hline Configuraçáo $\mathbf{n}^{\circ} \mathbf{2}$ & Teste 3 & Teste 4 \\
\hline Configuraçấo $\mathbf{n}^{\circ} \mathbf{3}$ & Teste 5 & Teste 6 \\
\hline
\end{tabular}


A informaçáo obtida nos testes realizados é composta por um conjunto de pontos cotados ao longo dos alinhamentos pré-definidos (Figura 6), a partir dos quais são depois construídos os perfis de praia.

O equipamento usado para medir os perfis de praia possui uma grande resolução vertical $(0,0005 \mathrm{~m})$, sendo a maior altura das formas de fundo formadas ao longo da superfície de praia (ripples) maior que a menor variação entre pontos cotados. De forma a evitar a transposiçáo para o perfil da informação acerca destas formaçóes foi usada a técnica da média móvel simples (MMS), para o alisamento dos perfis medidos, Figura 7. A MMS corresponde ao cálculo da média de um determinado grupo de pontos cotados do perfil, dito móvel pois a cada novo ponto considerado abandona-se o mais afastado. Neste caso, a cada ponto do perfil foi atribuído o valor médio dos 3 pontos consequentes na série de dados transmitida pelo perfilador.

Os perfis definidos ao longo do tempo de ensaio permitem analisar o seu desenvolvimento, retirando informação quanto à sequência e volume das alteraçóes registadas. $\mathrm{Na}$ Figura 8 são apresentados os perfis construídos com base nos dados recolhidos no $4^{\circ}$ ensaio ao longo do $1^{\circ}$ alinhamento, permitindo relacionar a sua evolução com o tempo de ensaio.

Da análise da Figura 8 pode concluir-se que o perfil obtido ao fim de 8 horas de solicitação não constitui um perfil de equilíbrio, uma vez que em relação ao perfil imediatamente anterior, este ainda apresenta uma ligeira evolução. Esta constatação vai de encontro à informação de Chen \& Kuo (1994) indicando que seria necessário prolongar por mais tempo o ensaio, de modo a atingir o perfil de equilíbrio. No entanto, a ordem de grandeza das diferenças registadas no período de teste definido é satisfatória, permitindo a realização da comparação pretendida. A mesma figura permite ainda verificar que a variação do perfil vai assumindo menor expressão à medida que o tempo vai avançando.

A análise particular de cada alinhamento de praia não transmite informação suficiente acerca da distribuição espacial das alteraçôes produzidas sobre a superfície de praia. A Figura 9 apresenta o a configuraçáo tridimensional da superfície de praia no final de 8 horas de solicitação do $4^{\circ}$ ensaio, construída com recurso a um software de desenho de superfícies a 3 dimensóes (Surfer 9), que relaciona os dados obtidos nos 5 perfis. A imagem transmite de forma clara a forma final da superfície da praia, sendo também visíveis pequenas ondulaçôes devidas à influência dos ripples registados.

A avaliação da evolução do perfil é complementada pelo cálculo das diferenças de cotas registadas ao longo do ensaio segundo cada um dos alinhamentos. A Figura 10 é composta pelo gráfico relativo à variação total das alturas registadas ao longo do perfil no 5 durante o $1^{\circ}$ e $2^{\circ}$ ensaios (Configuração $\left.\mathrm{n}^{\circ} 1-\mathrm{TP}=10 \mathrm{~s}\right)$.

Como é possível verificar na Figura 10, apesar de filtrados através da técnica da média móvel a informação recolhida ainda é influenciada pelos ripples formados na praia do modelo. No sentido de precaver interpretaçóes incorretas das variações de altura registadas, foi atribuída uma margem de incerteza de valor igual à altura do maior ripple formado, cerca de 15 a $20 \mathrm{~mm}$.

A variação das cotas registadas permitem comparar a influência das alteraçôes verificadas nos perfis controlados e as zonas ao longo dos mesmos onde se verifica a deposiçáo ou erosão de sedimentos. Através da conjugação das diferenças calculadas para cada alinhamento definido é possível construir mapas como os da Figura 11, recorrendo ao mesmo software usado para a construção das superfícies 3D.

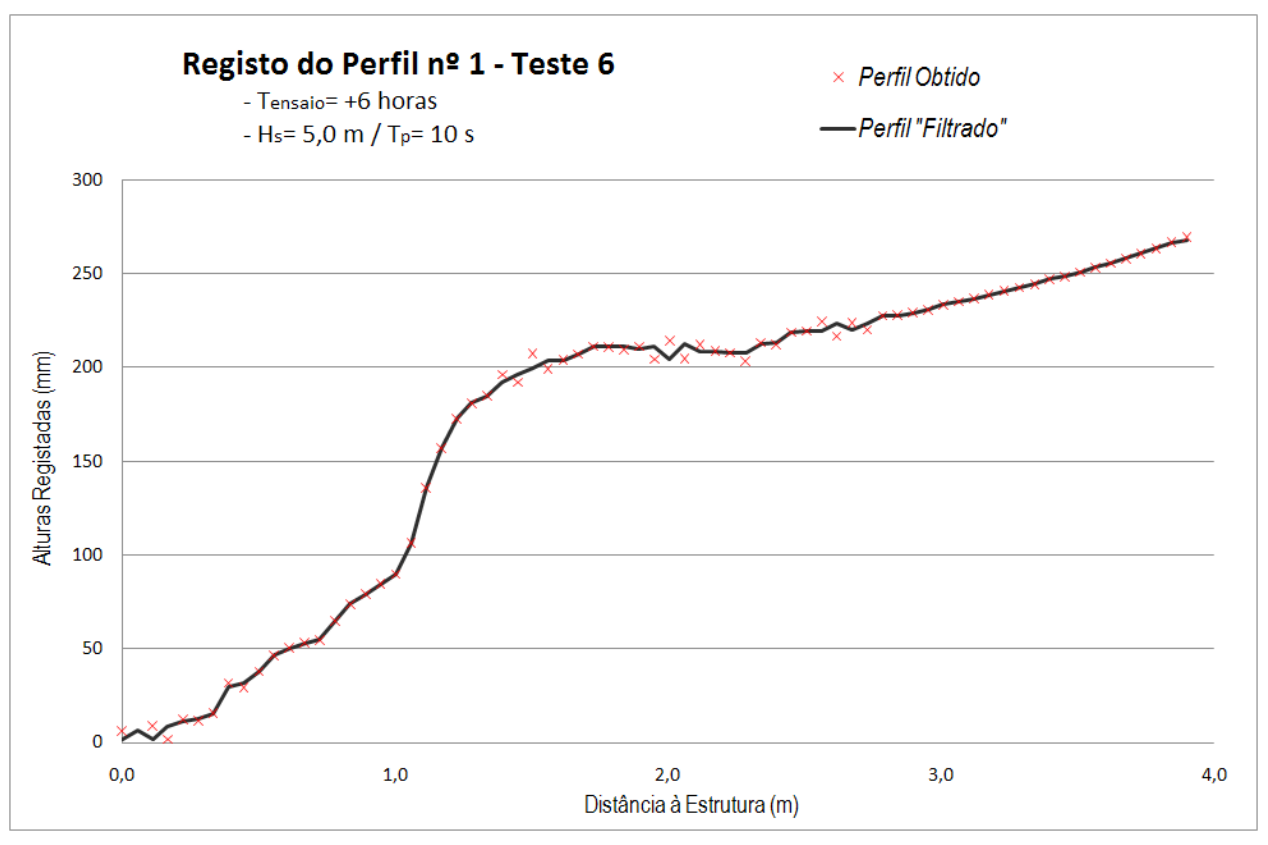

Figura 7. Perfil no $1-3^{\text {a }}$ configuração (+6 horas). Figure 7. Profile $n^{\circ} 1-3^{\text {rd }}$ configuration ( +6 hours). 


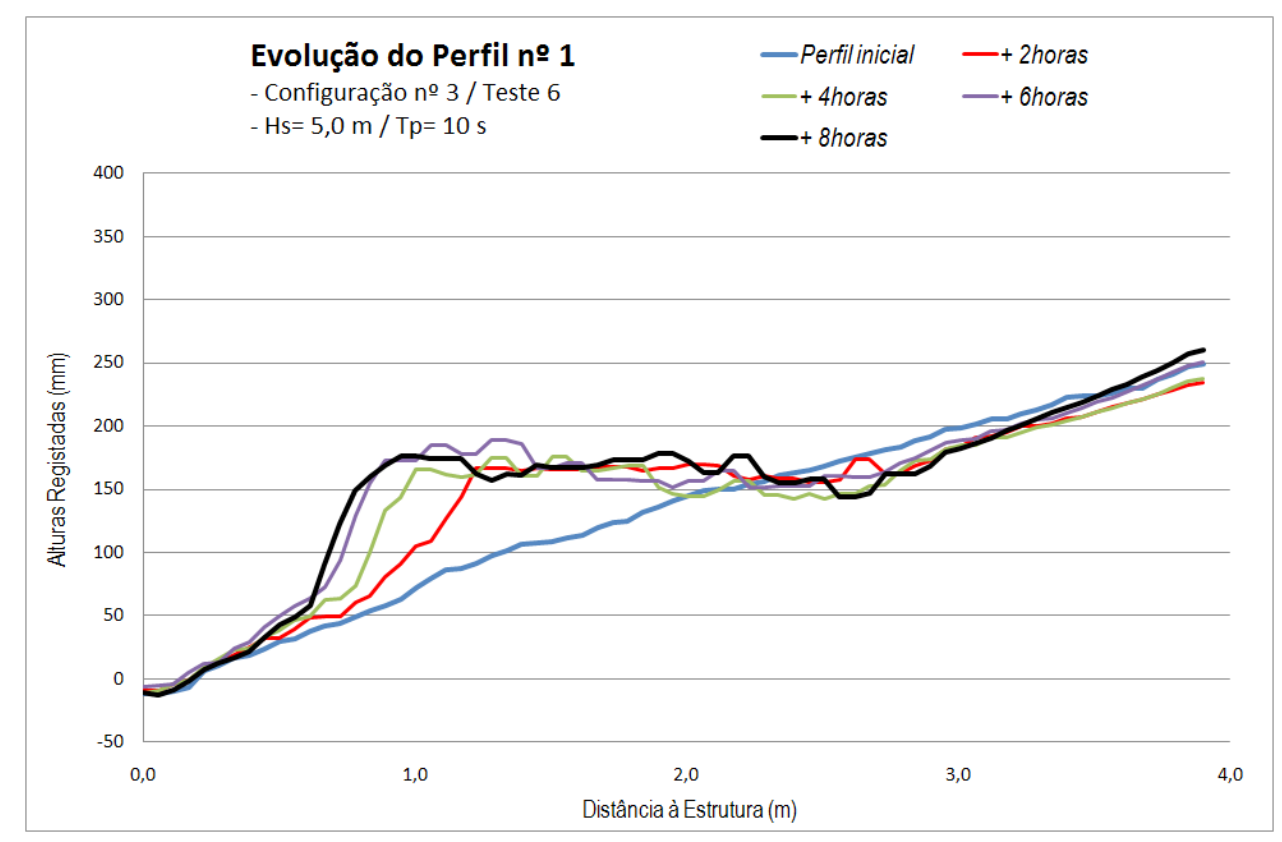

Figura 8. Evolução temporal do perfil no 1 - Teste $n^{\circ} 4$.

Figure 8. Time evolution of profile $n^{\circ} 1$ - Test no. 4.

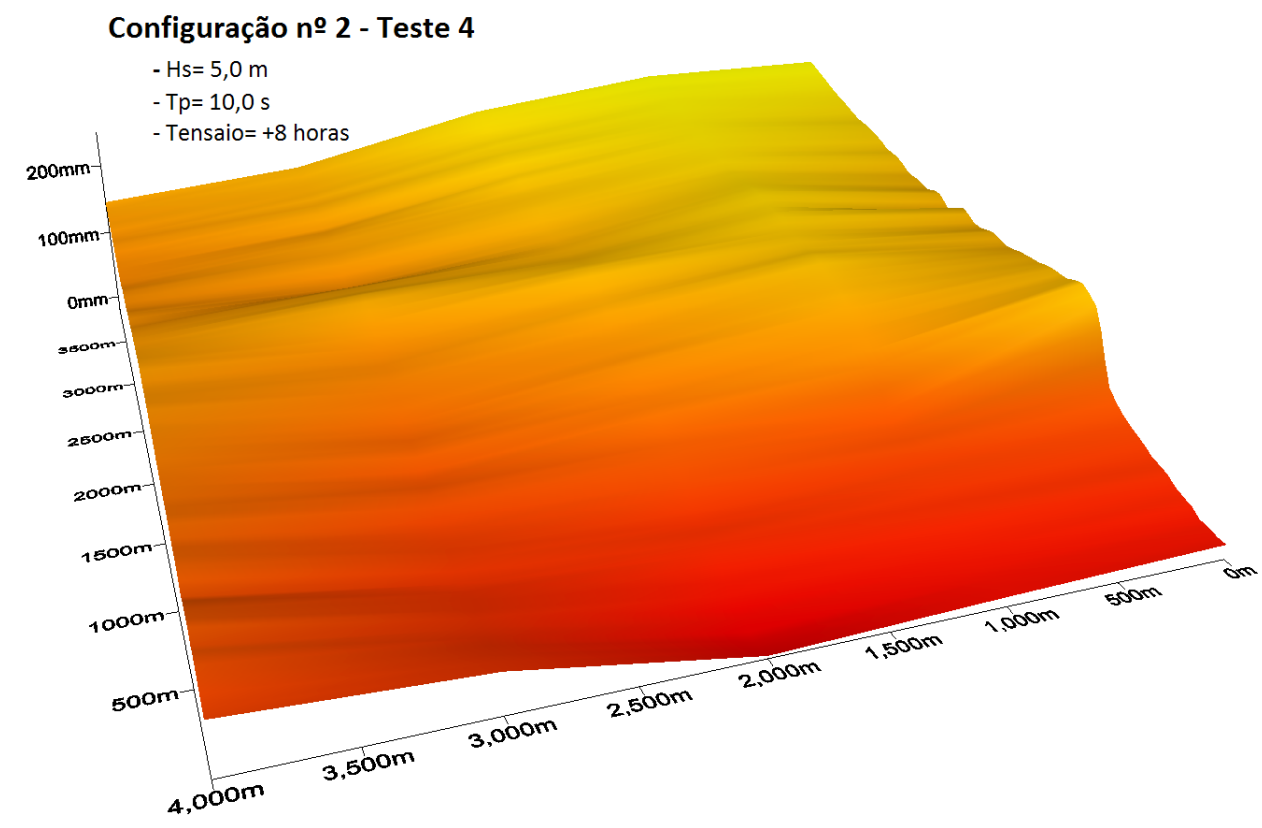

Figura 9. Representação 3D da superfície da área de medição ao fim de 8 horas - Teste no 4. Figure 9. 3D representation of the control area surface after 8 hours - Test no. 4. 


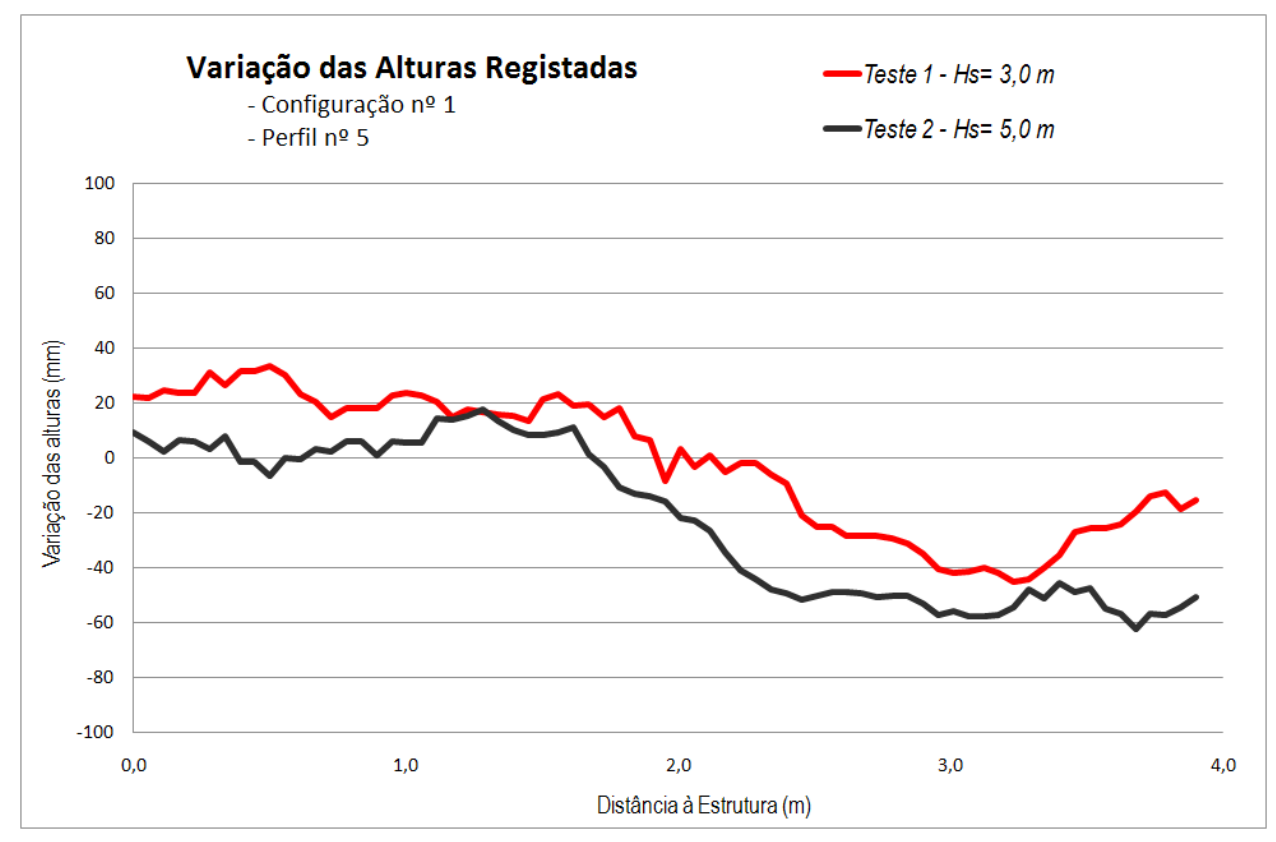

Figura 10. Variação total das alturas registadas para o pernil no 5 - Teste no 1 e 2 .

Figure 10. Total variation of the registered heights on profile no. 5 -Tests no. 1 and 2.

\subsection{Alteraçáo do estado de agitação}

As condiçôes de agitação consideradas foram repetidas em testes efetuados com as diferentes configuraçóes, sendo o único fator de distinção a altura de onda significativa. Os resultados obtidos permitem identificar desigualdades quanto à forma, evolução e volumes envolvidos nas alteraçôes dos perfis verificadas durante o tempo de ensaio.

Através dos mapas de variação total das cotas registadas, construídos com base na informaçáo obtida sobre os perfis controlados, como os apresentados na Figura 11, é possível notar diferenças na resposta morfológica do modelo, quando submetido às ações dos distintos estados de agitação.

A informaçáo fornecida pelos cálculos, gráficos e mapas criados indicia que a maior capacidade energética do estado definido por uma altura de onda significativa maior promove, como seria de esperar, a maior capacidade de transporte das areias da praia. Nos mapas construídos (Figura 11) é visível a maior extensão das áreas cujo valor e variação de cota é, em módulo, superior à margem de incerteza definida.

O agravamento das solicitaçóes a que o modelo é sujeito traduz-se, de forma coerente em todos os testes realizados, pelo alargamento da área de deposiçáo das areias, a partir da zona central do modelo, nos testes cuja altura de onda significativa é menor, para as zonas de influência dos perfis 2 e 3 (ver Figura 6), dirigindo-se para a faixa lateral à estrutura, como pode ser comprovado na Figura 12.

A zona de deposição de sedimentos apresenta ainda uma tendência para se aproximar do talude de tardoz do quebramar destacado quando o clima de agitaçáo gerado é mais intenso. No entanto a tendência demonstrada é contrariada pelo facto de, nestas condiçóes, devido às características da estrutura, se registarem galgamentos que alteram as correntes estabelecidas.
As zonas de erosão, por sua vez, estâo localizadas ao longo do corredor lateral entre a estrutura e o limite do modelo construído. A sua posição é semelhante em todos os ensaios realizados, embora sejam de assinalar diferenças relativamente à área e valor máximo. Mais uma vez, os testes definidos por uma altura de onda significativa maior traduzem-se em resultados de erosóes de maior dimensão e ao longo de áreas mais extensas.

\subsection{Redefiniçáo da configuraçáo do quebramar destacado}

O quebramar destacado construído representa, como referido, uma estrutura destacada disposta paralelamente à linha de costa, de forma a fazer um angulo reto com a direção de propagação da onda incidente. A secção, ao longo da zona central do quebramar, manteve-se inalterada durante a realização dos ensaios, tendo as reconfiguraçóes executadas incidido sobre as zonas de cabeça da estrutura.

A análise comparativa efetuada, procura investigar os dados recolhidos ao longo de uma série de testes caracterizados por uma condição de agitação semelhante, sendo o fator de diferenciação a configuração atribuída à estrutura. Os ensaios realizados sob um clima de agitaçáo mais severo, possuem uma maior capacidade de transporte das areias da praia, conferindo maior expressividade aos resultados obtidos e acentuando as diferenças na evolução da superfície da praia entre cada ensaio. Com base na informação dos perfis recolhidos em cada teste realizado, foram construídos os mapas de variação de cotas da área de controlo, apresentados na Figura 13, que constituem o ponto de partida para a análise realizada.

A partir desta figura encontram-se evidências de que as diferentes configuraçôes impostas à estrutura alteram 

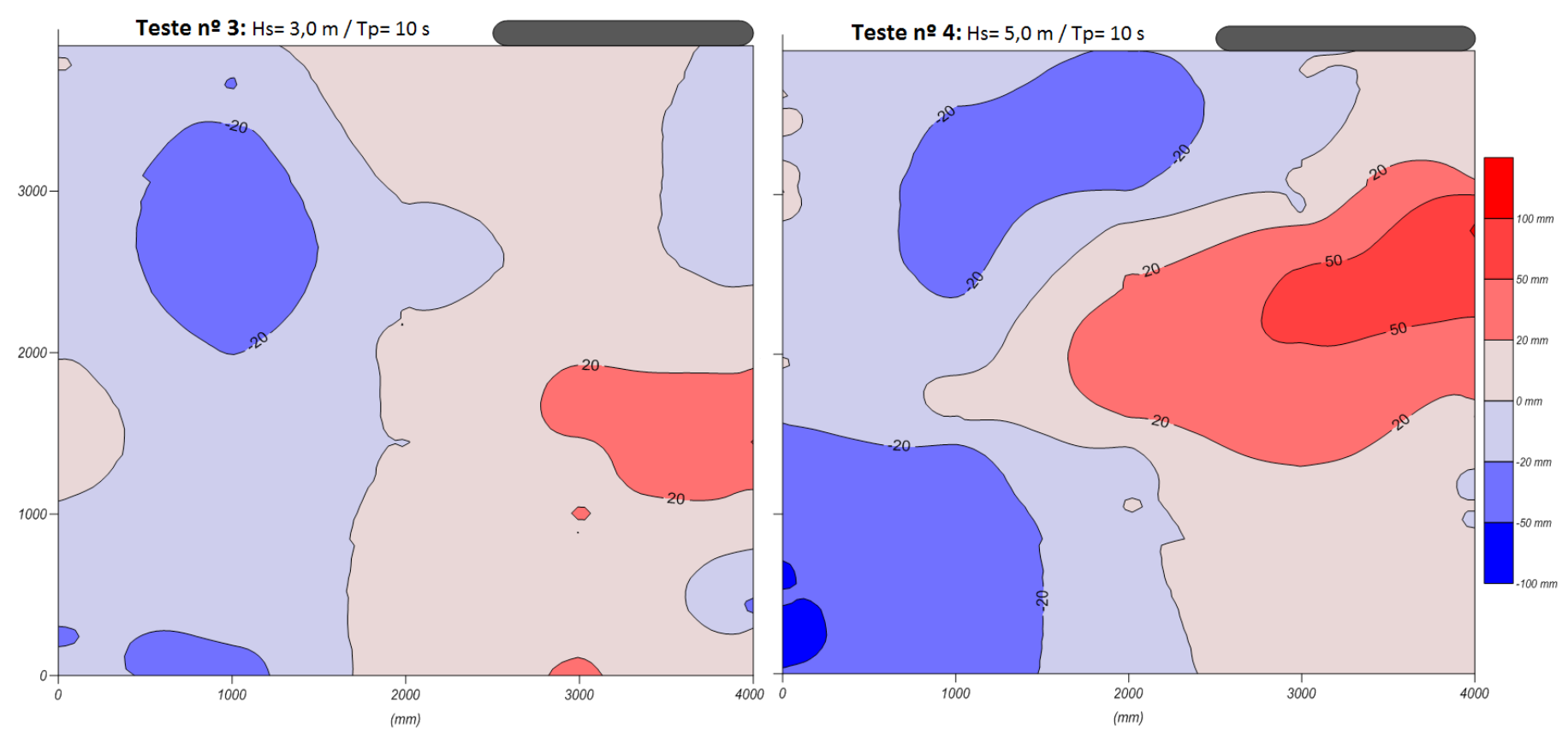

Figura 11. Mapa da variação de alturas registadas - Teste no 3 (à esquerda) e Teste no 4 (à direita) - Configuração no 2.

Figure 11. Registered heights variation maps - Test no. 3 (left) and Test no. 4 (right) - Configuration no. 2.

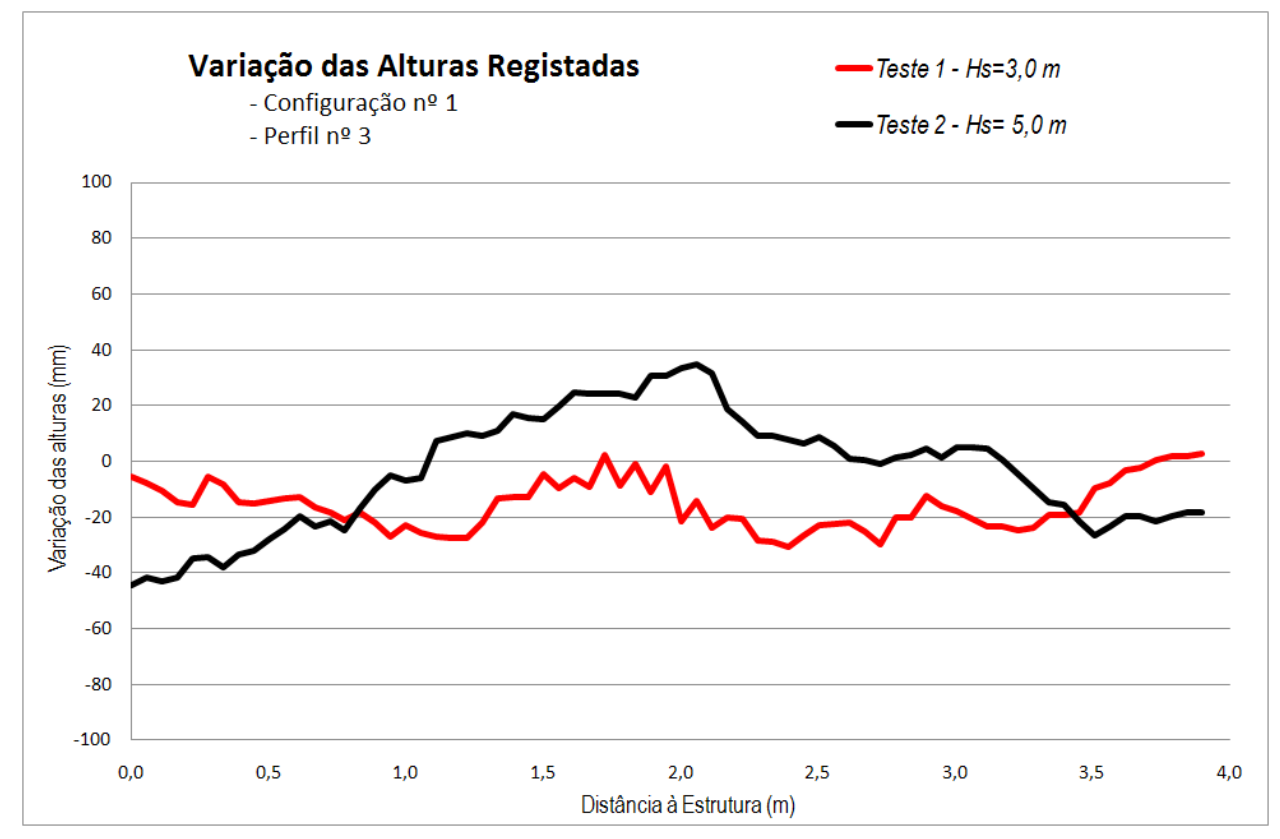

Figura 12. Variação total das alturas registadas - Perfil no 3, Ensaios 1 e 2.

Figure 12. Total variation of the registered heights on profile no. 3, Tests 1 and 2. 
as características da ação hidromorfológica da mesma, conduzindo a diferenças na evolução morfológica da praia adjacente. Com base nos mapas criados foram identificadas as zonas da praia de onde são extraídas as areias, assim como, as áreas para onde elas são transportadas. Durante os ensaios realizados não foi considerada nenhuma fonte adicional de sedimentos, pelo que as variaçóes de cota registadas devemse ao movimento das areias que constituíam a praia desde o início do teste.

Os mapas da Figura 13 assinalam a variação de cotas ao longo da superfície de praia criada para os diferentes ensaios realizados. A análise das figuras permite verificar que, de modo geral, a posição das zonas de variação positiva/negativa das alturas registadas é semelhante, sendo que, as areias da praia são retiradas de zonas laterais à estrutura criada, acumulando-se ao longo da zona protegida. Apesar de no global a evolução registada ser semelhante, é possível denotar diferenças significativas nos resultados obtidos, em relação as áreas de erosão e deposição de sedimentos.

A Figura 14 apresenta o gráfico da variação total de cotas registadas, segundo o $1^{\circ}$ alinhamento (ver Figura 6), para os ensaios definidos por um clima de agitaçấo com uma altura de onda significativa de $5,0 \mathrm{~m}$. O perfil $\mathrm{n}^{\circ} 1$ coincide com o eixo de simetria do modelo, atravessando a zona protegida pela estrutura, que lhe confere características favoráveis à deposiçáo das areias transportadas pela onda. Os 3 ensaios em análise demonstram tendências semelhantes de evolução do perfil $\mathrm{n}^{\circ} 1$, sendo comum a todos, a elevação da superfície de praia na zona mais próxima do quebramar, consequência da deposição das areias transportadas pela onda nesta área.

A mesma figura aponta algumas diferenças, quanto à definição final do perfil analisado, entre os testes realizados perante as 3 configurações definidas. $\mathrm{O}$ registo de variações positivas de altura do perfil de praia estende-se até uma zona mais alta da praia, afastando-se do talude de tardoz do quebramar, quando a estrutura é definida pela configuração $n^{\circ} 1$ (Teste 2) em relação aos restantes testes (Testes 4 e 6). Nestes casos, a variaçáo positiva de cotas do perfil, apresenta valores máximos mais elevados, não se prolongando em direção à linha de costa, como no teste $\mathrm{n}^{\circ} 2$. No caso da linha relativa à $3^{\text {a }}$ configuração (Teste 6 ), pode assinalarse na zona mais afastada da estrutura a tendência para o registro de variaçôes de cota negativas. Tal situação, deve-se ao refluxo de água após a rebentação da onda, que é neste caso suficientemente forte para arrastar as areias da praia em direção à estrutura, contribuindo para a aproximação da zona de maior acumulaçáo de sedimentos ao talude da mesma e maior amplitude da variação de cotas registada.

A Figura 15 traduz a variação total de cotas ao longo de do perfil $n^{\circ} 5$, relativamente aos testes $n^{\circ} 2,4$ e 6 . O perfil em análise encontra-se fora da zona sombra da estrutura destacada, estando por isso mais exposto à ação da onda. Nos testes referidos, verifica-se que existe uma variação negativa de cota da zona mais elevada do perfil de praia, comum a todos os ensaios, não se registando divergências significativas quanto a sua intensidade ou posição ao longo do perfil.

A zona de cabeça do quebramar é, segundo os mapas da Figura 10, caracterizada pela variaçâo negativa de cotas em todos os ensaios realizados, sendo este facto confirmado através da Figura 16, referente à variação total de cotas do perfil $n^{\circ} 3$ para os ensaios referidos anteriormente.

A análise da figura anterior, combinada com a Figura 13, permite verificar que a variaçấo negativa de cotas registada, é mais expressiva no caso da estrutura com a configuraçáo $\mathrm{n}^{\circ}$ 1. Esta configuração, não favorece a fixação das areias desta zona da praia, sendo vulnerável à ocorrência de erosóes, que colocam em risco a estabilidade e segurança do quebramar. As alteraçóes produzidas nas restantes configuraçóes possuem uma influência positiva na estabilização desta área, conduzindo a menores variaçóes de cotas ao longo dos ensaios. A transformaçáo produzida na cabeça do quebramar, substituindo a face plana e alinhamentos retos da $1^{\text {a }}$ configuração pela forma cónica das configuraçóes $n^{\mathrm{a}} 2$ e 3, elimina a transição brusca e imediata induzida na onda pela $1^{\text {a }}$, permitindo que a transposiçáo do quebramar pela onda incidente em direção à linha de costa, seja mais suave.
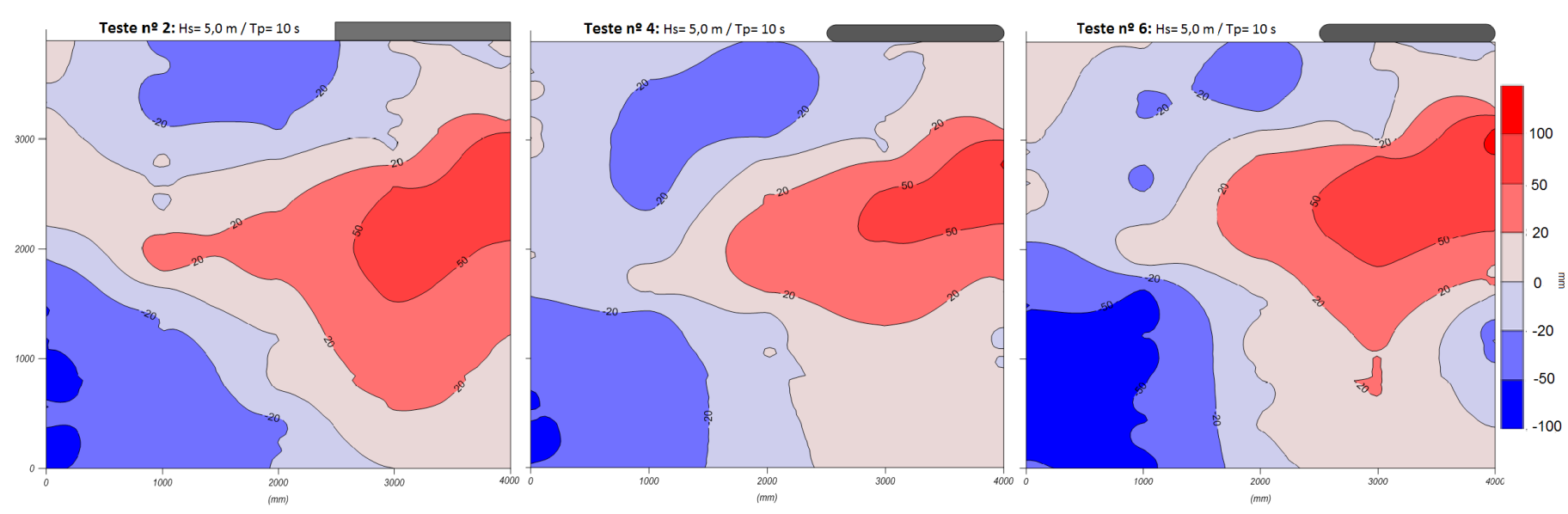

Figura 13. Mapa da variação de alturas registadas - Teste $n^{\circ} 2$ (em cima, à esquerda), teste $n^{\circ} 4$ (em cima, à direita) e teste $n^{\circ} 6$ (em baixo). Figure 13. Registered heights variation maps - Test no. 2 (above, on the left), test no. 4 (above, on the right) and test no. 6 (down). 


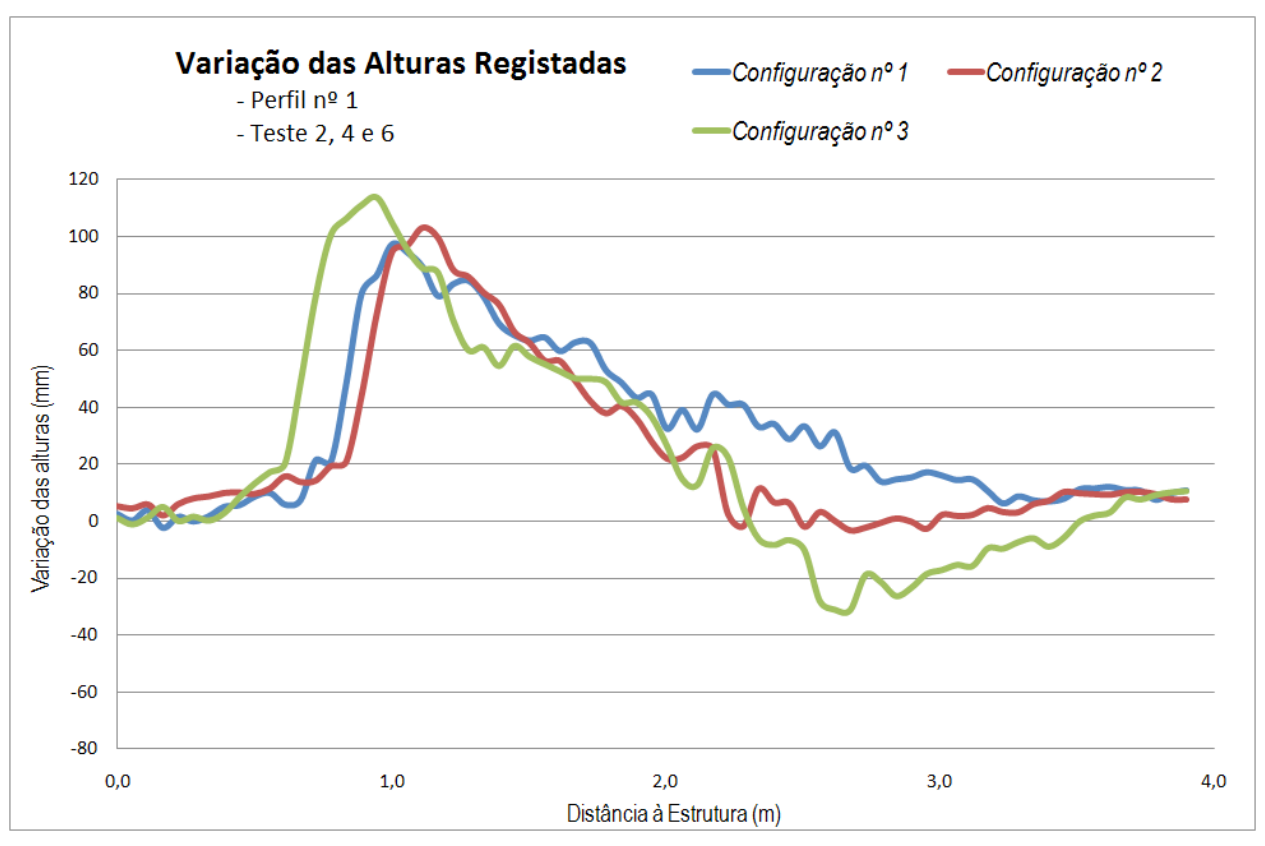

Figura 14. Variação total das alturas registadas - Perfil no 1, Testes 2, 4 e 6.

Figure 14. Total variation of the registered heights on profile no. 1, Tests 2, 4 and 6.

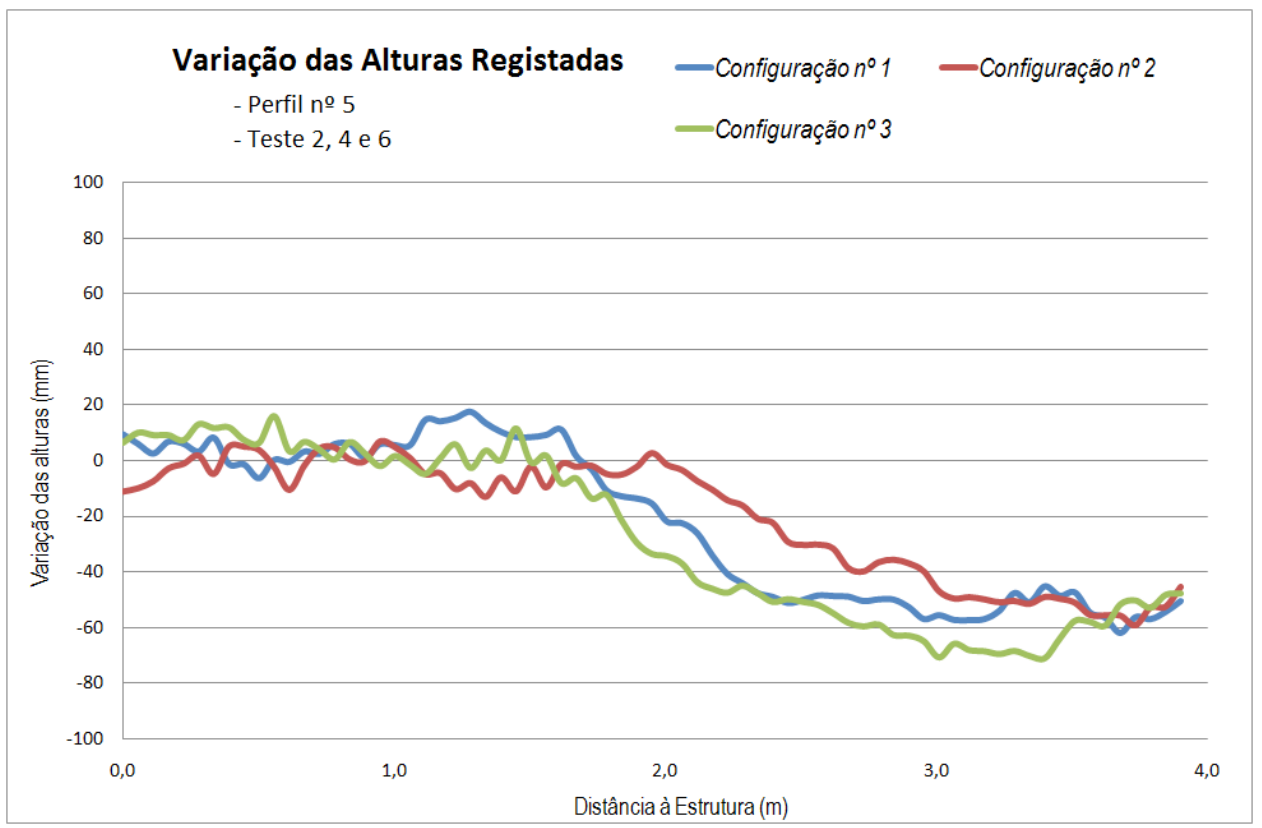

Figura 15. Variação total das alturas registadas - Perfil no 5, Testes 2, 4 e 6.

Figure 15. Total variation of the registered heights on profile no. 5, Tests 2, 4 and 6 . 


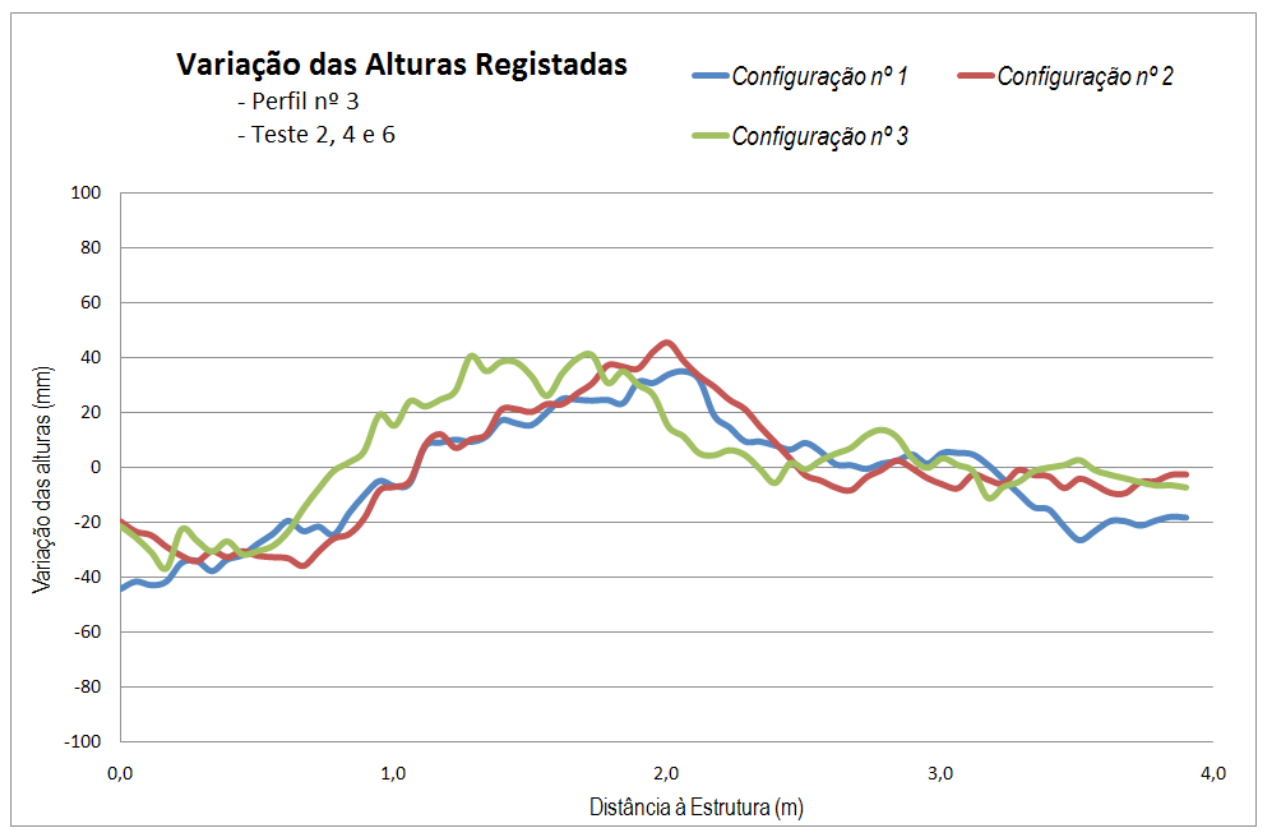

Figura 16. Variação total das alturas registadas - Perfil no 3, Testes 2, 4 e 6.

Figure 16. Total variation of the registered heights on profile no. 3, Tests 2, 4 and 6 .

\section{CONCLUSÓES}

O trabalho experimental apresentado neste artigo teve como principal objetivo o estudo da influência de 3 configuraçóes da cabeça de um quebramar destacado na evolução de uma praia, quando submetido a duas condições de agitação características da costa oeste portuguesa, relacionando o desenvolvimento registado ao perfil de praia, com a interferência dessas mesmas configuraçóes na propagação da onda incidente e também com as condições de agitação geradas.

A evolução do perfil de praia para as diferentes configurações do quebramar destacado, e diferentes condiçôes hidrodinâmicas, foi analisada e quantificada. Durante os ensaios verificou-se que a capacidade de transporte da onda aumenta à medida que a altura de onda significativa aumenta também. Nos ensaios realizados, não foram observadas diferenças significativas nos padróes de transporte sedimentar em torno estrutura. A areia transportada é retirada de zonas ao longo das faixas laterais à estrutura, sendo depositada na zona sombra, ao longo do eixo central do modelo, mantendo-se assim constante o volume total de areia na praia. A ocorrência de galgamentos em alguns testes, com uma altura de onda significativa maior, instabiliza o padrão de recirculação de correntes na zona abrigada pelo quebramar, reduzindo a expressão das diferenças registadas.

Os resultados obtidos demonstram também que estruturas com uma configuração similar à da configuração no 1 , são vulneráveis à ocorrência de fenómenos de erosão junto ao pé do talude na zona da cabeça do quebramar. Os dados sugerem que estruturas cuja forma da cabeça do quebramar se assemelhe às configuraçóes 2 e 3 , possuem maior capacidade de proteção destas áreas. A transição mais suave da onda nestes casos, favorece a estabilidade dos sedimentos aqui depositados, contribuindo assim, para a estabilidade dos blocos do manto resistente nestas zonas. É possível concluir, que as configuraçóes $n^{\circ} 2$ e 3 têm um efeito positivo na estabilidade global da estrutura.

A configuração no 3 demonstrou, através dos resultados obtidos, ser a melhor configuração de entre as estudadas, relativamente à estabilidade e segurança do quebramar. A forma cónica e o declive menos acentuado das suas cabeças, minimizam as erosôes localizadas junto ao pé do talude, transmitindo maior estabilidade aos blocos que compóem a estrutura. Desta forma, os encargos ligados à manutenção da estrutura serão reduzidos e as operaçóes de reabilitação do quebramar menos frequentes, em relação às restantes configuraçóes. No entanto, o volume de material utilizado é maior, sendo por isso o custo associado à sua construçáo maior.

Os resultados ilustram claramente, embora não globalmente, devido ao número limitado de testes a importância do correto conhecimento da interação agitação marítima-estruturasedimentos e da otimização das características geométricas da estrutura, auxiliando em fase de projeto a escolha de uma opção de gestáo costeira que evite alguns dos possíveis impactos negativos, ou melhore os positivos.

\section{BIBLIOGRAFIA}

Burcharth, H.F.; Hawkins, S.J.; Zanuttigh, B.; Lamberti, A. (2007) - Environmental Design Guidelines for Low Crested Coastal Structures. 400p., Elsevier BV., Amsterdam, The Netherlands. ISBN: 978-0080449517.

Chen, W.J.; Kuo, C.T. (1994) - Study on the Sand Deposited Behind Detached Breakwaters. In A.S. Arcilla, M.J.F. Stive \& N.C. Kraus (eds.), Proceedings of the International Conference on Coastal Dynamics '94, pp. 938-949, ASCE, Barcelona, Espanha. 
China, R. (2011) - Modelação Física de Quebramares Destacados. 187p., Dissertação de Mestrado, Faculdade de Engenharia da Universidade do Porto, Porto, Portugal. Não Publicado.

Costa, M.; Silva, R.; Vitorino, J. (2001) - Contribuição para o Estudo do Clima de Agitação Marítima na Costa Portuguesa. 2as Jornadas Portuguesas de Engenharia Costeira e Portuária, Associação Internacional de Navegação, Sines, Portugal:

Costa, G. (2009) - Modelação de Quebramares Destacados. 219p., Dissertação de Mestrado, Faculdade de Engenharia da Universidade do Porto, Porto, Portugal. Disponível em http://hdl.handle.net/10216/57573

Gomes, F.V. (2007) - A Gestão da Zona Costeira Portuguesa. Revista de Gestão Costeira Integrada (ISSN: 16468872), 7(2):83-95, Lisboa, Portugal. Disponível em: http://www.aprh.pt/rgci/pdf/rgci7f2_1_velosogomes.pdf

Gomes, F.V.; Pinto, F.T.; Neves, L.; Barbosa, J.P (2006) - A European Initiative for Sustainable Coastal Erosion. Pilot Site of River Douro - Cape Mondego and Case Studies of Estela, Aveiro, Caparica, Vale do Lobo and Azores. 317p., Instituto de Hidráulica e Recursos Hídricos, Porto, Portugal. ISBN: 972-752074x.

Mangor, K. (2004) - Shoreline Management Guidelines. 294p., DHI Water \& Environment, HØrsholm, Denmark. ISBN: 87-98195050
Neves, A.C.V. (2007) - Análise do campo de pressóes em quebramares submersos. 266p., Dissertação de Doutoramento, Faculdade de Engenharia da Universidade do Porto, Porto, Portugal. Disponível em http://hdl. handle.net/10216/65571

Pereira, C.; Coelho, C. (2013) - Mapas de Risco das Zonas Costeiras por Efeito da Ação Energética do Mar. Revista de Gestão Costeira Integrada, 13(1):27-43. DOI: 10.5894/ rgci325

Pereira, G. (2008) - Projecto de um Quebramar Destacado de Protecção para a Frente Maritima de Espinho. 222p., Dissertação de Mestrado. Faculdade de Engenharia da Universidade do Porto, Porto, Portugal. Disponível em http://hdl.handle.net/10216/59143

Silva, R. (2010) - Avaliação Experimental e Numérica de Parâmetros Relacionados com Modelos de Evolução da Linha de Costa. 488p., Dissertação de Doutorado, Faculdade de Engenharia da Universidade do Porto, Porto, Portugal. Disponível em http://hdl.handle.net/10216/58492

Taveira-Pinto, F. (2002) - Análise das Oscilaçôes e dos Campos de Velocidades nas Proximidades de Quebramares Submersos, sob a Acção da Agitação Maritima. 305p., Dissertação de Doutoramento. Faculdade de Engenharia da Universidade do Porto, Porto, Portugal. Disponível em http://hdl.handle.net/10216/11852 